\title{
Property rights regimes and the management of resources
}

\author{
Mehmet Bac
}

\begin{abstract}
The property rights regime is an important link between the yield of a natural resource and the appropriation and maintenance incentives of its users. This paper discusses the theoretical background for this link and provides insights as to the function of the property rights regime, drawing from recent developments in the economics literature on optimal ownership patterns and the theory of repeated games. The performances of different resource ownership patterns are evaluated using the criterion of economic efficiency. The economic theory of property rights is based on the idea that, because contractual arrangements are bound to be incomplete, there is scope for opportunistic behaviour and therefore the resulting resource management is likely to be inefficient. Optimal resource ownership patterns are viewed as solutions to the problem of structuring private users" incentives in accordance with the socially desirable management of resources. (1) 1998 United Nations. Published by Elsevier Science Ltd. All rights resenicd
\end{abstract}

Society interacts with nature through technology, and in particular its institutions, the rules and conventions used for goveming behaviour. The design of institutions or property rights regimes that are in tune with the functions of the underlying ecosystem is a fundamental concern in successful and sustainable management of natural resources. The allocation of property rights for alternative uses of a natural resource has important income distribution, efficiency, economic and environmental consequences. This paper presents several aspects of what is currently known of the interaction between communities and natural resources under different property rights regimes, and how that interaction may affect the performance of the resource systems.

The theoretical results presented in this paper draw substantially on recent developments in the economics literature on property rights. In order to make the presentation accessible to the non-specialist and given the technical nature of this documentation, most of the supporting technical evidence or detail has been omitted and the reader is referred to the literature in question. From the economic viewpoint, a stock of natural resources is a productive asset, which depreciates if overused and which has to be maintained and managed efficiently in order to generate the highest yield. The property rights regime is important to the successful management of the resource, as it influences the motivations of those who exercise these rights or work with the resources.

The property rights regime may be imposed by the government or by local authorities, or it may be developed historically and enforced as a communal norm. Changes in

The author is Professor of Economics at Bilkent University, Bilkent, Ankara. the fundamental 'parameters' of a natural resource (i.e. its yield, intensity and predictability) may generate changes in the property rights regime. For instance, a territorial management system can become a looser, communal arrangement if resource use becomes less intensive. It can degenerate into an open-access system if local common property institutions cease to function, say, due to government intervention. Berkes (1989) provides a concrete example in his study of the hunting rights system of the native Indians in James Bay in sub-arctic Canada, where the ownership regime originally involved communal territories. Subsequently, as the use of the resource (mainly beaver) intensified following the development of the fur trade, a system of family-controlled territories evolved. Competition among fur companies and the incursion of outsiders into the area caused these local institutions to become eroded and finally lost.

A striking feature of the vast empirical literature studying the link between property rights regimes and economic performance is the sheer diversity of property rights regimes, especially in those resource management systems that are historically rooted. For example, in the reef and lagoon tenure systems of Oceania there is a diverse array of arrangements that changes from island group to island group (Ruddle and Akimichi, 1984; Johannes, 1978). Compared to this diversity, resource management prescriptions of the West are rather uniform in nature. To accommodate environmental and social perturbations, the task should be to make institutional arrangements more diverse, and the management of the resource more. flexible not less. It is therefore an essential research objective to improve our understanding of the performance of property rights regimes in relation to natural resource and communal attributes.

The criterion used in this paper to assess the 'success' in natural resources management is efficiency. Sustainability 
and efficiency are distinct concepts. A resource management pattern may be efficient, but fail to satisfy a sustainability criterion. Roughly, resource use $\mathrm{X}$ is said to be more efficient than resource use $Y$ if it is possible to make a number of individuals better off without harming the rest of the community by switching from resource use $Y$ to resource use $X$. Under certain technical assumptions, this definition is equivalent to saying that the total economic surplus generated for the community under resource use $\mathrm{X}$ is larger than under resource use $Y{ }^{\prime}$ Often, many efficient uses of natural resources coexist and the choice involves inevitable welfare trade-offs between social groups (landlords and peasants, rural people and industrial groups), and trade-offs between present and future generations. A clearly defined and operationalized concept of sustainability may be of help in resolving these trade-offs. However, efficiency has priority: we must first tackle the problem of maximizing the size of the cake given the ingredients, before discussing how it should be distributed between present and future generations and between the poor and the rich within the present generation. To the extent possible, we must separate income/welfare distribution concerns from efficiency concerns.

The following two sections of this paper are devoted, respectively, to a definition of property rights regimes and a discussion of incentive consequences. The subsequent section focuses on a special and controversial property rights regime that is often observed in rural communities: the local commons. A popular proposition, the Hardin (1968) "tragedy of commons", is not a very good characterization of what really happens in many commons cases. Much of the commons literature instead suggests a "bucket brigade' metaphor. ${ }^{2}$ Given a resource management problem, a group of people will organize themselves and allocate property rights in a way that is similar to the formation of a bucket brigade to put out the fire in a rural community. The tragedy of the commons arises only if the link between the management regime and the resource users is destabilized by a shock, such as technological innovations, government intervention or sharp fluctuations in the commercial yield of the resource. The theory of repeated games provides insights, summarized below, as to when a stabilizing feedback is present and when it may deteriorate.

\section{Property rights regimes: definition}

This section provides a definition and classification of property rights. It also prepares the ground for the next

\footnotetext{
'The most important technical assumption is that the utilities of individuals be 'quasilinear' (see Mas-Colell et al., 1995). The second definition of efficiency which relies on the measurement of total surplus is much more operational than the first, because it is almost impossible that a structural change as important as a switch in the ownership regime harms no one in the society while improving the welfare of certain individuals. However, if the gains outweight the losses, that is, if the total surplus for the community increases as a result of the change in the ownership regime, it will be possible to compensate the losers for their losses and yet leave the winners with a positive surplus. The regime switch will enhance efficiency provided that the losers can be compensated.

${ }^{2}$ Some of this literature is captured and interpreted in a series of volumes by the National Research Council (1986), McCay and Acheson (1987), Ostrom et al. (1988), Stevenson (1991), and Bromley (1992). These volumes account for only a traction of the writings on this subject.
}

section, which discusses the determinants of property rights regimes and their implications for renewable resource management.

Why should the efficient management of a resource or asset be affected by the distribution of property rights pertaining to the various uses of the resource? What dnes it mean to own a natural resource, such as a piece of land or a flow of water? It is very useful to view a resource not simply as an object, but rather as a collection of rights, each of which can be separately owned by, or transferred to, different individuals or groups. What rights can be associated with, say, a 4 ha maple forest? This is a composite resource, which promises a stream of future goods and services. It can be used consumptively, e.g. for physical construction works, it can be sold or leased, or it can be spatially divided into territories. By analyzing the rights attached to the uses and services of a natural resource, one can separate its ownership into, for example, the right to graze in the forest for 20 years, the right to revenues from tourism and recreational services, and the right to collect and commercialize specific food items such as mushrooms or maple syrup. Some of these services and associated rights may be in conflict, and hence may not be exercised simultaneously. Some are simultaneously exercised, as by, for example, an international paper company which manages its forest resources for both wildlife and timber, or as in the Huerta system in Valencia (Spain) which forbids the separation of water rights from the land being used. Negative or positive externalities may stipulate a coordinated exercise of the various rights associated with a resource.

The list of rights to all potential goods and services that can be produced from a natural resource, and the circumstances under which the corresponding user rights can be exercised can be extended indefinitely, but it is bound to remain incomplete, due to uncertainty, lack of knowledge, limitations of the human intellect and the time needed to conceive such a list. Moreover, property rights must be enforceable; otherwise they cannot be transferred nor exercised. These facts have profound implications for the ownership structure: there will be a party (the government, an individual or group of individuals) who owns all the rights except those that are restricted by law or conferred to other parties through contracts. That is, there will be an owner of residual rights who, in accordance with the recent theory developed by Grossman, Hart and Moore (see Grossman and Hart, 1986 and Hart and Moore, 1990) is simply called 'the owner'. The criterion of efficient management of the resource determines who this owner should be, and what rights should efficiently be conferred to whom through contractual relationships.

The above definition of ownership is adopted here, and reference is made to the mechanisms for allocating these rights to natural resources as property rights regimes. Since natural resources can provide a large number of services, property rights regimes are likely to be diverse and complex. This article distinguishes between open access regime, government ownership of the resource base, and private ownership of the resource base.

\section{Open access regime}

Property rights in this rather extreme case are simply not allocated. Rights belong to no one; hence the resource is 
open to all. An open access regime can be efficient only if the 'shadow price' of the resource is zero, that is, if there is no social cost of extracting or using a marginal unit of the resource. This requires that the resource stock be quite large relative to the size and needs of the community, admittedly a rather hypothetical case in the present world context.

\section{Government ownership of the resource base}

The owner (of residual rights) under this regime is the government, which represents the general public. The government may contract out specific user rights to private individuals or firms. This type of mixed regime is sometimes referred to as hybrid ownership and the resulting management is called co-management (see, for instance, de Camino Veloso, 1987, Jentoft, 1989, Ruddle, 1989 and Pomeroy, 1994 for case studies on the workings and performance of co-management systems). An example of co-management would be the private management of a national forest by a firm for 20 years, where all remaining rights belong to the government. The private management may, of course, be subject to regulation.

\section{Private ownership of the resource base}

Under private ownership, the owners of residual rights are private individuals. The regime may display a hierarchical structure of property rights allocations, as the owners may contract out specific user rights to other private individuals. (A common term for contracting out specific rights associated with the land resources, such as the rights to access and manage, is tenancy.) An example of a private ownership system is a local fishery holding all the rights over the fish resources in a small lake. Each fisherman in the group may enjoy these rights subject to the informal rules and norms set forth by the group of owners, and the formal rules set forth by law. Here, two opposite private ownership regimes comes to mind-one where the resource is co-owned, and one where it is not:

1. shared private ownership (for example, a common property resource);

2. individual private ownership.

Shared private ownership differs from open access regimes in one important way: the number of individuals with access to the benefits of the resource is fixed under the first regime, and is unlimited under the second.

Alternatively, property rights regimes can be classified according to whether the resource is physically divided into separate parcels or seen as a single unit (Dasgupta, 1993). Ownership will thus be either separated by territorial boundaries or pooled together and attributed to an entire community, which in practice means, in most cases, the people living in the resource area. The first case corresponds to a territorial ownership regime, the second corresponds to a common property ownership regime. The local fishery situation quoted above is an example of common property resource ownership; family-scale farming is an example of territorial ownership.

Underlying each property rights regime is an enforcement mechanism, which is usually provided by a legal code. However, a property rights regime may be self-enforcing in the sense that the owners' rights need not be protected externally by law or police force but may be enforced by the owners themselves, informally, through norms and rules as in the case of local commons. Specifications of the rights to the services of a natural resource may vary in precision; vagueness and incomplete specification of ownership rights may give rise to conflict over access to and management of the resource. The lack of a clear and enforceable property rights regime generates incentives to over-exploit the resource base and underinvest in its maintenance. This is an important point, sharpened in the proposition below.

\section{Proposition 1}

A precondition for the successful management of a natural resource is a precise relationship between property rights and their holders. Vague ownership structures tend to generate the consequences of open access regimes.

A suggestive example is the legislation regarding surface waters in Turkey, which, under current laws, are no-man's property, that is, in principle open access resources. In the past, courts have allocated water-user rights on the basis of priority of appropriation (see FAO, 1993). This type of legislative deficiency regarding ownership certainly contributes to the degradation of surface water quality: with free access, users will tend to over-extract water, since they are not paying for it. The allocation of user rights on the basis of priority of appropriation will not necessarily achieve efficient management. An example at the international level is the conflict between Turkey, Syria and Iraq over user rights to the transboundary rivers Euphrates and Tigris; this conflict is a direct consequence of the lack of clear, enforceable and accepted rules for the extraction of water. If such rules were in place, the parties would be able to reach an agreement on the allocation of water and a more controlled situation would result (see Bac, 1996 for a game-theoretic analysis of the interaction between nations under incomplete information about national objectives).

The time period for which property rights are granted and recognized is another aspect where uncertainty can lead to serious maintenance failure. For example, a private enterprise holding the right to manage a forest will abstain from investing in planting new trees and upgrading the resource, if its expected planning horizon is short, due to the inability of the owner (typically the government) to make a credible commitment to provide secure tenure.

\section{Property rights regimes: determinants and. implications}

The preceding section has laid down general principles and attributes of property rights regimes. The variety of property rights regimes for natural resources is immense. What lies behind this variety? What are the implications of property rights regimes on the yield or surplus of a natural resource? These questions are addressed below.

The propositions highlighted in this section about the relationship between property rights regimes and efficiency in resource management are closely related to the interested parties' ability to write and enforce comprehensive contracts. Such contracts are fictitious, ideal instruments to organize economic relationships; a complete contract can specify an indefinite number of aspects and uses of the 
resource for the present and the entire future in utmost detail. How costly is it, and to what extent is it possible (or beneficial) to contract out the services of a piece of land or a flow of water? The answer has implications for determining the most efficient property rights regime. It appears logical to derive the following proposition from the insights of Coase (1937), Alchian and Demsetz (1972), and Williamson (1985).

\section{Proposition 2}

Resources with yields and services for which contracting out would be too costly are more efficiently governed by a concentrated ownership regime.

In a concentrated ownership regime, property rights are held by a small number of individuals. Such a regime appears to devolve from the relatively high costs of contracting out the various services of the resource. It may be too costly for the owner of a forest (say, the government) to lease and regulate separately the rights to harvest the various yields of the resource. In such cases, as stipulated by the efficiency consequences in proposition 2, it may be observed that either the government or a private party exercises all these rights together. The costs may originate from many contextual facts, such as the degree of uncertainty involved, the lack of knowledge, and asymmetric information that can potentially generate opportunistic behaviour. For instance, the cost of contracting out the right to collect mushrooms or fodder may stem from the impossibility of monitoring the users for their external effects on other yields of the forest. Forests are mostly under full public ownership precisely because the externality and enforcement costs involved in managing the various services through dispersed ownership regimes more than offsets the potential benefits (in the form of better technical efficiency, inherent in the exercise of property rights under private management). A corollary of proposition 2 is that lower costs of contracting out various uses of the resource (presumably through improved monitoring technologies or legislation) will generate incentives to transform a concentrated ownership regime into a dissipated one.

The main point of the discussion so far is that if complete contracts are feasible, that is, if all potential uses of the resource can be costlessly specified in contracts and enforced, the actual ownership patterns observed should generate efficient management. ${ }^{3}$ However, the actual situation is far from approximating this 'ideal'. If the costs of writing separate contracts for various aspects and uses of the resource are prohibitively high, several factors become crucial to an efficient ownership regime. The first of these

\footnotetext{
${ }^{3}$ This statement is a version of the well-known Coase theorem, though Coase refers to "costless negotiations" in his formulation instead of the notion of complete contracts. The statement is true even in the presence of externalities because complete contracts can specify and enforce, without cost, the parties' duties in dealing with externalities. Complete contracts would specify with the utmost precision what compensation should be paid to the victims and the extent of the extemality-generating activities. As Coase also points out, under costless negotiations (or complete contracts), the allocation of rights (that is, the ownership regime) is immaterial to the efficient management of resources. The ownership regime matters when contracts are incomplete. The discussion below should thus be viewed as a second-best analysis, where the ownership regime is viewed as a second-best solution to managing resources efficiently.
}

factors is the distribution of inputs that complement the resource in production. The complementary inputs in question are not tradeable, such as resource-specific information and local expertise in the cultivation of various crops. Efficiency requires the following.

\section{Proposition 3}

Holders of non-tradeable and non-contractible inputs that complement natural resource use should also be the owners of the resource. This will provide stronger incentives for efficient management.

Aside from income distribution concerns, a strong reason why local people should hold a wider set of rights over local commons is that they hold resource-specific, non-tradeable inputs. Jodha (1993) has documented the potential adverse effects on local people's incentives to manage and upgrade the commons as new legislation has partially curbed their rights, in particular those regarding access. Proposition 3 also provides a rationale for 'community involvement', that is, why communities should be transferred the rights to participate in decisions conceming the management of local natural resources; this provides the local people with the opportunity and incentive to use their resource-specific information.

The second important determinant of an efficient ownership regime relates to the investment incentives of the users. As with all productive assets, environmental resources require maintenance investment. The soil depreciates during the process of agricultural production and needs upkeep in order to generate a sustainable yield. Here, the property rights regime plays an important role, as it affects the owners' or users' incentives to undertake the optimal level of investment into the resource base. The theory of ownership based on incomplete contracts stipulates the following proposition.

\section{Proposition 4}

When it is too costly to govern private investment decisions by contractual arrangements (or to enforce them through contracts or supervision), efficiency requires that the investing party be the owner of the resource.

If long-term contracts that transfer the full benefits of investment are too costly to write and enforce, one alternative remains to restore optimal investment incentives: that the investing party should own the resource. This will entitle the investing party to the full future stream of benefits from investment, hence providing incentives to adopt the optimal pattem of investment. To recapitulate, these arguments rely on the assumption that complete long-term contracts are not available, that is, resource users cannot be induced to undertake the optimal level of investment through contractual arrangements. These arguments also depend on whether access to credit is perfect or not. This issue is briefly discussed below. Many examples attest to the use, whenever possible, of long-term contracts or commitments. One instance is in Australian range-lands, where the state leases land to private farmers. In certain cases the lease is perpetual, but even when it is not, it may apply for decades (Pickup and Morton, 1995). In Kenya, the provision of security of tenure (which amounts to a long-term commitment) is reported to have reduced soil erosion due to its positive effects on farmers' investment incentives. 


\section{Public investment}

An important type of investment to which the statement in Proposition 4 does not apply is public investment, such as the search for and implementation of technological improvements in present and future productivity of the resource. The training of local people for better resource use may also be included in this category. Such technological improvements are not to be seen as private investments but public investments par excellence as, once produced, they potentially benefit all. Public investment goods are not marketed as are private investment goods such as machines and equipment. They generate important positive externalities, and should therefore be provided by governments or non-profit organizations.

\section{Owners' access to credit}

Resource owners' access to credit is another important issue. Poor local people with resource-specific knowledge and ability may not hold any property rights-but they should, according to proposition 3 above. Even if they own the resource that provides them with a living, they may lack the investment funds needed to upgrade the resource. If capital markets are imperfect (a pervasive condition in developing countries), they fail to allocate funds to many potential uses with high rates of return and thus generate overall investment and management inefficiency (proposition 4). There are two possible solutions to this problem.

\section{Proposition 5}

1. There is room for efficiency-enhancing government action when access to credit by owners or users of a resource is imperfect. The government may act as a banker and provide credit on reasonable terms. The relevant considerations in this regard are the efficiency of government credit operations, the availability of information regarding the borrowers' needs and incentives, and the extent to which public funds crowd out private funds (the latter are likely to be managed more efficiently).

2. Large, credible parties have better access to credit. On pure efficiency grounds, concentration of the ownership of the resource will produce better investment policies and management, other things being equal.

The reasons for the lack of credit, especially to the rural poor, are deeply rooted in informational asymmetries between potential borrowers and creditors. The latter lack relevant information about the expected rate of return (which the former possess) and their ability to pay back (known as the adverse selection problem) and about the care with which the funds will be used (known as the moral hazard problem). In these circumstances, lack of collateral means lack of credit. The government could fill this gap as stipulated in item 2 of proposition 5 , but the problem of asymmetric information would still remain, especially with respect to the users' ex-post incentives to manage the credit. Coping with the 'moral hazard' problem is costly because it requires monitoring of credit users. However, institutional reforms may partially overcome the information problem. An example is the rural credit programme initiated by the Grameen Bank in Bangladesh (see Varian, 1990 for a theoretical analysis). The bank offers loans to groups of small farmers without collateral requirement, but the members of a group are made liable for each other's debt. This scheme transfers the burden to monitor credit users from the bank to group members by inducing them to monitor each other, quite a creative solution to the moral hazard problem. As stated in item 2 of proposition 5, groups, being a larger entity than individuals, are more credible and have access to more credit on better terms. The default rate on loans by the Grameen Bank has been impressively low, about $2-3 \%$.

\section{Resource-specific factors}

Resource-specific factors can be grouped together as the third important determinant of an efficient ownership regime. The most important of these factors are density (the average value of harvest per unit area) and predictability (the inverse of the variance in the value of the resource per unit time in the unit area). The consequences of these factors in terms of ownership are summarized and explained below.

\section{Proposition 6}

High density and predictability of the resource favour private ownership regimes whereas low density and predictability favour common property with dispersed and mobile communities (Dasgupta, 1993).

Under private ownership, each owner is exposed to a yield risk that under common ownership is shared, insuring the members to a certain extent. The need for insurance against fluctuations in the resource yield increases as predictability falls, and vice versa. Thus, other things being equal, when the resource yield is predictable and its density sufficiently high, a private ownership regime parcelling the land among the individuals within a given group will be more efficient because it copes better with the problems of investment and maintenance than does the common ownership regime. Common ownership regimes are mostly effective in dry lands with a relatively high yield uncertainty, while private ownership predominates in agricultural areas with stable rainfall and weather conditions.

The above discussion has focused on efficiency consequences of property rights regimes, ignoring their income distribution consequences. Common property resources, the subject of the next section, are mostly observed in rather poor communities; these systems generate a more even income distribution and are of great importance to the poorest within rural populations.

\section{A close look at common property resources}

In terms of the classification of property rights regimes introduced above, common property resources may be govemed by shared private ownership regimes or government ownership regimes with community participation in its management. A resource is likely to be commonly owned or managed when its territorial division is either not feasible (such as the fish in the lake) or very costly to enforce. The principal characteristic of these resources is the presence of reciprocal externalities. The actions of each user affect the 
well-being of all other users as, for instance, the grazing of one user's cattle on the common pasture affects the other cattle owners. What may be an optimal act from the perspective of one individual's self-interest is mostly not optimal from the community's perspective, as in the case of water withdrawals from a common pool, where the individually optimal amount will often exceed the socially optimal amount. Thus, the crucial determinant of a community's success in managing a common resource is its ability to build institutions that internalize the externalities and consequences of individual actions. Common property resources are not open access resources. The owner community, as a whole has strong incentives to limit access to its land or forests and enforce its property rights against encroachers. However, successful management of the resource requires more. Individual members must have an incentive to cooperate in achieving communal efficiency, each must be induced to take into account the fact that their own actions affect the quality of the resource base. Common property resources will suffer overexploitation if the members leave it unmonitored. This bad outcome, for which Hardin (1968) coins the term 'tragedy of the commons', is not inevitable. The theory of repeated games, applied to the particular context of local commons, provides interesting insights. It tells us that, under specific conditions, cooperative outcomes can be sustained among a group of self-interested agents with conflicting objectives. What are these conditions?

\section{Proposition 7}

A community will develop self-enforced institutions that monitor the use of the common resource, and punish those who misuse it, if economic and natural environments are sufficiently stable and expected to remain so. Rupidly increasing community populations, technological breakthroughs, central government interventions and large fluctuations in the prices of harvested products are factors that contribute to the collapse of a community's own monitoring and enforcement institutions.

All the destructive factors mentioned in this proposition work their effects through the same intermediate variable: the incentives of the individual community members. The self-enforcement mechanism collapses and the stage is set for the 'tragedy of the commons' when the individual's short-term private gains from not conforming to the informal rules of communal efficiency exceed his longterm private gains from sustained compliance. A rapid increase in the population decreases the per-member share from the common's output, and hence decreases the individual's gain in complying. ${ }^{4}$ Perhaps surprisingly,

\footnotetext{
${ }^{4}$ Consider the example of a local fishery. For instance, when generation of the maximum sustainable yield stipulates a catch rate of $I$ ton per period, a population of 10 leaves $100 \mathrm{~kg}$ per head, whereas a population of 100 leaves $10 \mathrm{~kg}$ per head. In the latter case, an individual fisherman's sustained gain from conforming with the catch rate of $10 \mathrm{~kg}$ is much too low; it may even be lower than his short-term private gain from extracting the individually optimal amount, say, for example, $200 \mathrm{~kg}$. It may be worth extracting $200 \mathrm{~kg}$ for a while and risking punishment by other members of the community instead of conforming to the community's $10-\mathrm{kg}$-per-head catch rule. It is not hard to guess what happens if each fisherman deviates from communally optimal rules of catch. Increases in the population will build up the individual's incentive to deviate from communal rules, which potentially leads to the extinction of the fish population and collapse of the local fishery.
}

technological breakthroughs such as tractorization may also have adverse effects on local commons. As in the Jodha (1993) case study, with the introduction of a new cropping technology into the local commons, individuals become better equipped for extracting larger private short-term gains from the resource. Furthermore, individual members will be tempted to expropriate the resource, which may in turn generate long-lasting intra-communal conflicts.

Common ownership regimes deal with externality problems by establishing institutions that monitor individual users and enforce patterns of resource use. They may have a cost advantage over private ownership regimes in dealing with extemalities to the extent that their conflict resolution mechanisms are more efficient, equitable and respected. Given these institutions and mechanisms, the key issue is the robustness of the common ownership regime to perturbations in the incentives of individual members (to deviate from or conform with the rules and regulations of the commons). This issue is further developed below.

McKean (1993) raises an interesting question with respect to commercialization of the harvest of a common resource: When are commercial temptations damaging and when are they just fine, or even the raison d'etre of a common property resource? Empirical evidence is inconclusive. In some cases, an increase in the price of the items extracted from the common resource leads to the collapse of the regime, whereas in other cases, such as coastal fisheries, the regime copes fairly well with increases in the users' temptations to over-extract the common resource. The theory of repeated games applied to the context of a local common resource provides a very useful guide to the answer. The answer suggested by the theory hinges on the comparison between two choices that the individual has, each choice being associated with a stream of benefits. In deciding whether to act cooperatively, a community member will weigh the long-term yields of cooperation against the short-term benefits of cheating, that is, acting according to his self-interest, ignoring the rest of the community. A permanent increase in the prices of the harvested items will increase both benefit streams, but relatively more so the benefits from sustained cooperation if the community members are 'patient' enough, that is, if they do not discount future benefits heavily. In relatively poor communities whose members are preoccupied by shortterm survival needs, the same increase in the prices of harvested items may, through the strong short-term temptation it imposes on the members, lead to the collapse of cooperative management. Another important consideration is whether the price increases are perceived as temporary or permanent, as the members will be more tempted to deviate from communal rules of resource use if prices are high only temporarily.

The transformation of common property resources into (non-shared) private properties may result in serious problems relating to their efficient management, as the new owners may fail to internalize the negative external effects of their activities. The empirical study produced by Jodha (1986) provides useful insights into the why and how of the collapse of local commons. Jodha's study covers dryland commons in India over a period of 20 years. During that period, he observed declines in the geographical areas of the common property resource, ranging from 26 to $63 \%$, partly through privatization. An increased population, coupled with new technologies such as tractors, made it 
profitable to expropriate land for cropping. The outcome was gradual desertification. In one instance, it was a government land reform in the concerned area that triggered the desertification process; the reform did not include any investment into improving the productivity of the land base. Privatization of forest lands without enforcement of appropriate laws may also have fatal consequences. Binswanger (1989) reports a case from Brazil, where the government's policy of reducing taxes on agricultural income to zero has induced the relatively wealthy to acquire forest land, which is then deforested for cropping. The policy was a complete failure; it led to the destruction of marginal forest lands, rendered destitute the rural poor who depended on the forest, and worsened the income distribution. A desirable aspect of the common property regime is its relatively fair income distribution consequences. Common property resources also constitute a not negligible source of income for the poorest in rural communities. These two aspects are often neglected when public policies targeting local commons are designed.

The following proposition concludes this section and the article.

\section{Proposition 8}

Before designing an intervention with respect to a natural resource, it is of vital importance for policymakers to ascertain whether or not the resource is common property and whether or not it is currently managed by a functioning selfenforcement regime. If such is the case, any policy intervention may be counterproductive.

\section{Acknowledgements}

The author expresses his thanks to the FAO for providing financial and technical support, and to Mr. Maharaj Muthoo, FAO representative in Ankara, for stimulating conversations.

\section{References}

Alchian, A. and Demsetz, H. (1972). Production, information costs, and economic organization. American Economic Review, 62, 777-795.

Bac, M. (1996). Incomplete information and incentives to free ride on international environmental resources. Joumal of Environmental Economics and Management, 30, 301-315.

Berkes. F. (ed.) (1989) Common Property Resources: Ecology and Community-Based Sustainable Development. Belhaven, London.

Binswanger, H. (1989) Brazilian Policies that Encourage Deforestation in the Amazons. Paper 16, World Bank Environment Department.

Bromley, D. W. (ed.) (1992) Making the Commons Work: Theory, Practice and Policy. Institute for Contemporary Studies Press, San Francisco, CA.
Coase, R. H. (1937). The nature of the firm. Economica, 4, 386-405.

Dasgupta, P. (1993) An Inquiry inso Well-Being and Destitution. Oxford University Press, Oxford, UK.

de Camino Veloso, R. (1987) Incentives for Community Involvement in Conservation Programmes. FAO, Rome.

FAO (1993) National Action Programme, Republic of Turkey. FAO, Rome.

Grossman, S. and Hart, O. (1986). The costs and benefits of ownership: a theory of vertical and lateral integration. Journal of Political Economy, 94, 691-719.

Hardin. G. (1968). The tragedy of the commons. Science, 162, 0.

Hart, O. and Moore, J. (1990). Property rights and the nature of the firm Joumal of Political Economy, 98, 1119-1158.

Jentoft, S. (1989). Fisheries co-management: delegating government responsibility to fisherman's organizations. Marine Policy, 13, 137154.

Jodha, N.S. (1986). Common property resources and rural poor in dry regions of India. Economic and Political Weekly, 21, 1243-1248.

Jodha, N. S. (1993) Property Rights and Development. Beijer Discussion Papers Ser. 41, Stockholm, Sweden.

Johannes, R. E. (1978) Traditional marine conservation methods in Oceania and their demise. Annual Review of Ecology and Systematics 9, 349364.

Mas-Colell, A., Whinston, M. D. and Green, J. (1995) Microeconomic Theory. Oxford University Press, Oxford, UK.

McCay, B. J. and Acheson, J. M. (eds) (1987) The Question of the Commons. University of Arizona Press, Tucson, AZ.

McKean, A. M. (1993) Empirical Analysis of Local and National Property Rights Institutions. Beijer Discussion Papers Ser. 42, Stockholm, Sweden.

National Research Council (1986) Proceedings of the Conference on Common Property Resource Managenent. National Academy Press, Washington, DC.

Ostrom, V., Feeny, D. and Picht, H. (eds) (1989) Rethinking Institutional Analysis and Development. Institute for Contemporary Studies Press, San Francisco, CA.

Pickup, G. and Morton, S. R. (1995). Restoration of arid lands. In Defining und Mecwsuring Sustainability: The Biogeographical Foundations, eds M. Munasinghe and W. Shearer. The United Nations University and The World Bank.

Poineroy, R. S. (ed) (1994) Cominumity Managesnent and Cominon Property Coastal Fisheries in Asia and the Pacific: Concepts, Methods and Experiences. International Center for Living Aquatic Resources, Manila.

Ruddle, K. (1989) Solving the common-property dilemma: village fisheries rights in Japanesc coastal waters. In Common Property Resources; Ecology and Community-Based Sustainuble Development, cd. Fikret Berkes, pp 168-184. Belhaven Press, London.

Ruddle, $\mathrm{K}$ and Akimichi, T (1984) Maritime institutions in the Western Pacific. Senri Ethnological Studies, 17. National Museum of Ethnology. Osaka, Japan.

Stevenson, G. G. (1991) Common Property Economics: A General Theory of Lund Use Applications. Cambridge University Press, Cambridge, UK.

Varian, H. R. (1990). Monitoring agents with other agents. Journal of Institutional and Theoretical Economics, 146, 153-174.

Williamson, O. (1985) The Economic Institutions of Capitalism. The Free Press. 